especial detenimiento en la Constitución de Bayona (1808), de la que es consumado especialista. Todas las conferencias tuvieron lugar en inglés y fueron seguidas de animados debates.

M. J. Torquemada SÁnchez

\title{
PROYECTOS DE INVESTIGACIÓN Y TESIS DOCTORALES
}

\section{Departamento de Derecho Financiero y Tributario}

En la actualidad existen tres Proyectos de Investigación en curso de ejecución:

- Proyecto del Plan Nacional de I+D+i FINPROFUN, Núm. Ref. DER 2015-65832-P, La protección de las libertades fundamentales $y$ los derechos bumanos en el ordenamiento financiero y tributario, cuyo investigador principal es Miguel Ángel Martínez Lago, catedrático de Derecho Financiero y Tributario de la UCM.

- Proyecto CERTIFICARSE, Núm. Ref. DER 2015-6537-R, Efectos jurídico-financieros y control del impacto social para el desarrollo sostenible, cuya investigadora principal es Amparo Grau Ruiz, profesora titular de Derecho Financiero y Tributario de la UCM.

- Proyecto Núm. Ref. DER 2012-36510, Medidas fiscales para promover la inversión extranjera responsable: aproximación jurídica y repercusiones contables e institucionales en las economías en desarrollo, cuya investigadora principal es también Amparo Grau Ruiz, profesora titular de Derecho Financiero y Tributario de la UCM.

\section{Departamento de Derecho Mercantil}

En la actualidad existen dos Proyectos de Investigación en curso de ejecución:

- Proyecto Núm. Ref. DER 2014-54519-P (2014-2017), El mercado del crédito tras la crisis económica y financiera: el nuevo sistema espanol y europeo de regulación y supervisión bancaria (II), cuyo investigador principal es José Carlos González Vázquez, profesor titular de Derecho Mercantil de la UCM. 
- Proyecto Núm. Ref. DER 2015-68733-P (2016-2019), Reestructuración de empresas y Derecho de la Competencia, cuya investigadora principal es Juana Pulgar Ezquerra, catedrática de Derecho Mercantil de la UCM.

\section{Departamento de Derecho Romano}

El profesor Rodríguez Martín forma parte de los siguientes Proyectos:

- Como investigador principal, junto con Raquel Martín, del Departamento de Filología Clásica de la UCM, del Proyecto Núm. Ref. FFI 2015-65511-C2-2-P (2016-2019), Interpretación y análisis de los textos en papiro de las colecciones españolas: sociedad, religión y Derecho, de la UCM. El proyecto se ha concedido como subproyecto coordinado con el Proyecto Nacional DVCTVS, encargado de la conservación, catalogación, edición y difusión de las colecciones papirológicas españolas. En concreto, el subproyecto concedido se responsabiliza del análisis de los papiros documentales y jurídicos de las más relevantes colecciones españolas.

- Como miembro de Proyecto DOCEMUS-CM, Núm. Ref. S-2015/ HUM-3377 (2016-2018), Red digital para un milenio de documentación epigráfica en museos y archivos de la Comunidad de Madrid, de la UCM, cuya investigadora principal es Isabel Velázquez Soriano, y también del Proyecto para el desarrollo de las actividades del Grupo de Investigación Multidisciplinar del Mundo Antiguo TEAPIMEG, Núm. Ref. 930750, Textos epigráficos antiguos de la Península Ibérica, de la UCM, formado por dos subgrupos: Archivo Epigráfico de Hispania y Grupo Hesperia, dirigidos, respectivamente, por Isabel Velázquez y Eugenio R. Luján.

- Dentro de los Proyectos de Innovación Docente es director del Proyecto UCM 40, ROMA EN RED: docencia transversal entre tres disciplinas y aprendizaje colaborativo para la creación y difusión online de contenidos didácticos comunes. El proyecto se orienta al diseño y publicación, por parte de alumnos de Filología Clásica, Historia Antigua y Derecho Romano, de la web docente y de divulgación Leges Municipales on-line: http://www.ucm.es/derecho-romano/ leges-municipales-on-line. 
La profesora Laura Gutiérrez Masson, titular de Derecho Romano, forma parte del Proyecto Núm. Ref. DER 2016-74899-P, Claves histórico-jurídicas de la responsabilidad civil en derecho de familia, concedido por el Ministerio de Economía y Competitividad y la Agencia Estatal de Investigación, Plan Estatal de I+D+I 2013-2016, con una dotación de 24.000 euros. 